\title{
Improvement of clayey soil characteristics by using activated carbon
}

\author{
Kawther Al-Soudany ${ }^{1}$, Ahmed Al-Gharbawi ${ }^{{ }^{*}}$, Marwa Al-Noori ${ }^{1}$ \\ ${ }^{1}$ Building and Construction Engineering Department., University of Technology, Baghdad, Iraq
}

\begin{abstract}
The clay soil is weak and unable to carry the applied loads as a result of the weight of buildings or vehicles on the load performing on the soil. In this research, clay soil was grained and mixed with different percentages of activated carbon additives to investigate its performance. One type of clay soil from Al-Taji city was used. The percentages of activated carbon 3, 5, 7 and $9 \%$ were added to the soil and the influence of the admixture was observed by comparing the results with the untreated soil. The selected properties for this comparison were specific gravity, consistency limits, compaction, static compaction, CBR, consolidation, swelling and unconfined compressive strength. The results showed that the plasticity index, maximum dry weight and specific gravity decreased as the percentage of additives increased. The unconfined compressive strength increased as the percentage of additives and curing periods $\quad(1,7,14$ and 28 ) days increased. The amount of increase in soil strength was even more than $100 \%$ for the $9 \%$ activated carbon. The results showed that the addition of activated carbon has a positive effect to the geotechnical properties.
\end{abstract}

\section{Introduction}

For all engineering structures constructed on clayey soils, deformations occurr when these soils are exposed to any additional load or due to dissolution of clay when these soils are wet, soaked or leached with water. These deformations may cause a significant failure (cracking, tilting and collapse) of the foundation or earth structures.

Engineering properties such as strength, texture, workability, and plasticity are improved when adding some commercially manufactured additives to the soil in suitable quantities. The operation of blending and mixing some materials with soil, or blending soils together to improve certain properties, is called Stabilization. The benefit of mixing and addition is to achieve the required gradation or change gradient, texture, plasticity, and can act as a binder for cementation the soil. The methods of stabilization are divided into two methods as follows [1]:

a- Mixing the soils with several gradients to obtain material conforming to the required specifications can achieve the mechanical stabilization. Soil mixing can be carried out at the construction site, the central station, or the borrowing area. After that by using traditional methods, the mixture is spread and impacted to required density.

b- The addition of additives to the soil with different percentages of additives such as cement, lime, fly

*Corresponding author: ahmedsgharbawi@yahoo.com ash, bitumen, or a combination of these materials, will achieve additional mechanical stabilization. The soil classification and degree of improvement in required soil quality determines the percentage and type of additives to be used. Generally, to improve the characteristics of the soil such as gradation, workability, and plasticity requires a smaller amount of additives. Larger quantities of additive are used when needed to increase the strength and durability of the soil. And after the additives are mixed with the soil, spreading and compaction are achieved by conventional means.

This research concentrates on investigating experimentally the feasibility of stabilizing and improving the geotechnical properties of soft clay soil using activated carbon material in different proportions and studying The effect of activated carbon on the engineering characteristics of the stabilized clay.

\section{Experimental work}

\subsection{Materials used}

\subsubsection{Soil used}


A standard test was carried out on a brown soil fromAlTaji site (east Baghdad) to determine its physical and chemical properties. The soil's grain size distribution was $2.8 \%$ sand, $40 \%$ silt and $57.2 \%$ clay as shown in Figure (1). According to USCS the soil is classified as CL.

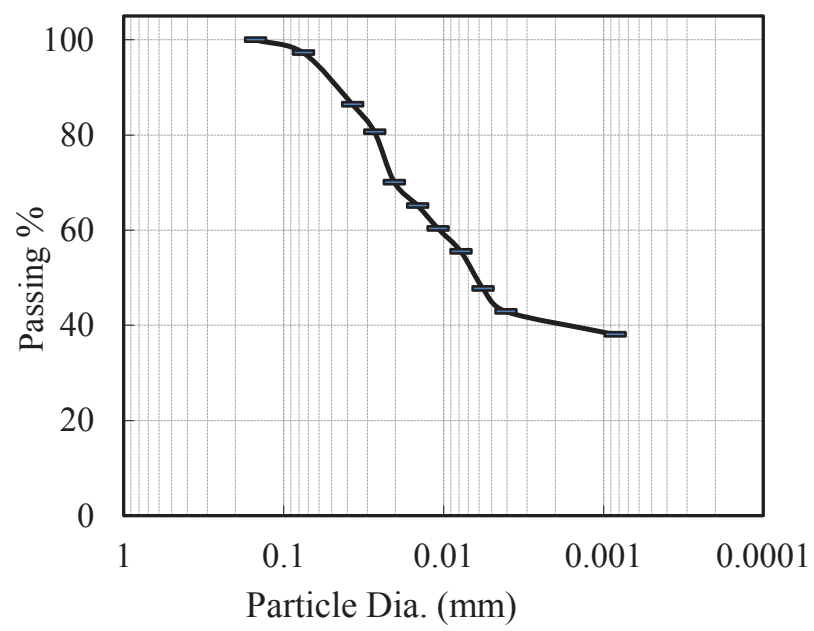

Fig. 1. Grain size distribution of Al-Taji soil

\subsubsection{Activated carbon}

The structure of many materials have a high amount of carbon content that can potentially be activated. Coal is one of the raw materials which can stabilize soils and contains (bituminous, anthracite and lignite), wood (both soft and hard), coconut shells, peat and petroleum based residues. Other raw materials have been evaluated such as peach pits, walnut shells, nutshell and but invariably their commercial limitation lies in raw material supply. The ranges for internal surface area and degree of porosity for the most of carbonaceous materials are between $10-15 \mathrm{~m}^{2} / \mathrm{gm}$ over activation, by controlled oxidation of carbon atoms usually achieved by the use of steam at high temperatures, the internal surface becomes highly porous and extended. After activation, depending on the plant operating conditions the internal surface area for carbon will be between 700 and 1,200 $\mathrm{m}^{2}$ [2].

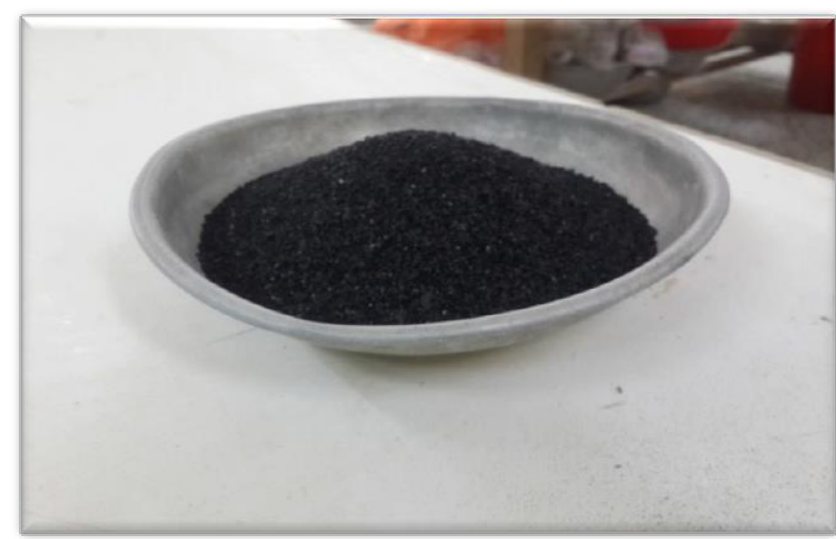

Fig. 2. Activated Carbon

\subsubsection{The Manufacturing of Activated Carbon}

There are two method of manufacturing activated carbon the first being treating raw material by chemical and the second by steam [3].

\section{1- Chemical method:}

The chemical activation is dependent on the raw materials used such as sawdust. The most commonly used activating agent used is phosphoric acid, whereas that there are good results for zinc chloride and sulfuric acid. The materials Which were used in past are calcium hydroxide, calcium chloride, manganese chloride and sodium hydroxide, and they are considered as dehydrating agents.

The raw material and reagent are mixed into a paste, dried and carbonized in a rotary furnace at 600 ${ }^{\circ} \mathrm{C}$. When phosphoric acid is the activating agent the carbonized product is further heated at $800-1000{ }^{\circ} \mathrm{C}$ during which stage the carbon is oxidized by the acid. The acid is largely recovered after the activation stage and converted back to the correct strength for reuse. The activated product is washed with water and dried.

Activity can be defined that the change limits between the raw material to activating agent, about $1: 05$ to $1: 4$. By increasing the concentration of the activating agent the same objective of the Activation can be achieved by increasing the control of furnace temperature and residence time.

\section{2- Steam method:}

The steam can be used for activation that applied to virtually all raw materials. The development of the all methods have the same principles of initial carbonization at $500-600{ }^{\circ} \mathrm{C}$ and followed by steam to react the activation at $800-1,100{ }^{\circ} \mathrm{C}$.

\subsubsection{Properties of activated carbon}

The properties of activated carbon that we are concerned in this project [3]:

\section{1- Surface area::}

The surface area of activated carbon reaches from 500 $\mathrm{m}^{2}$ to more than $2000 \mathrm{~m}^{2}$ and the surface area will increase by the increase of activated carbon finesse and it will decrease by the increase of its granular size.

\section{2- Apparent density:}

The activated carbons have density for the solid or skeletal between 2.0 and $2.1 \mathrm{gm} / \mathrm{cm}^{3} \quad(125-130 \mathrm{lbs}$ /cubic foot). Nonetheless, if the air volume of activated carbon takes a large space, then the actual or apparent density will be lower, typically 0.4 to $0.5 \mathrm{gm} / \mathrm{cm}^{3}$ (25-31 lbs/cubic foot). The good quality of activated carbon is provided at the high density which that provide a great volume.

\section{3- Hardness/abrasion:}

The measurement of activated carbon friction resistance is called hardness and abrasion and it is 
considered a very significant indicator for activated carbon to take part of its physical integrity and resist against frictional forces imposed by backwashing, etc. depending on the raw material and activity level.

4- Effect of oven temperature and adding water on activated carbon:

Activated carbon will not react with added water, it will adsorb the water because activated carbon has high porosity, and oven temperature of $110{ }^{\circ} \mathrm{C}$ in our experiment will not affect activated carbon.

\section{5- Particle size distribution:}

Activated carbon has fine particles size, which makes better access to the surface area and faster rate of adsorption kinetics. In vapor phase systems against pressure drop needs to be considered, which will affect energy cost. To provide significant operating benefits particle size distribution must be considered.

6- Structure

The ability of activated carbon can be dissected by appreciation of its structure. Much of the literature quotes a modified graphite like structure; the modification results from the existence of micro crystallites. It is formed during the carbonization process, which during activation have their proportionate bonding, disrupted causing free valences which are very reactive. In addition, the presence of impurities and process conditions effect the formation of interior vacancies, in the microcrystalline structures. Existence of pores generally explains faults in crystalline structures.

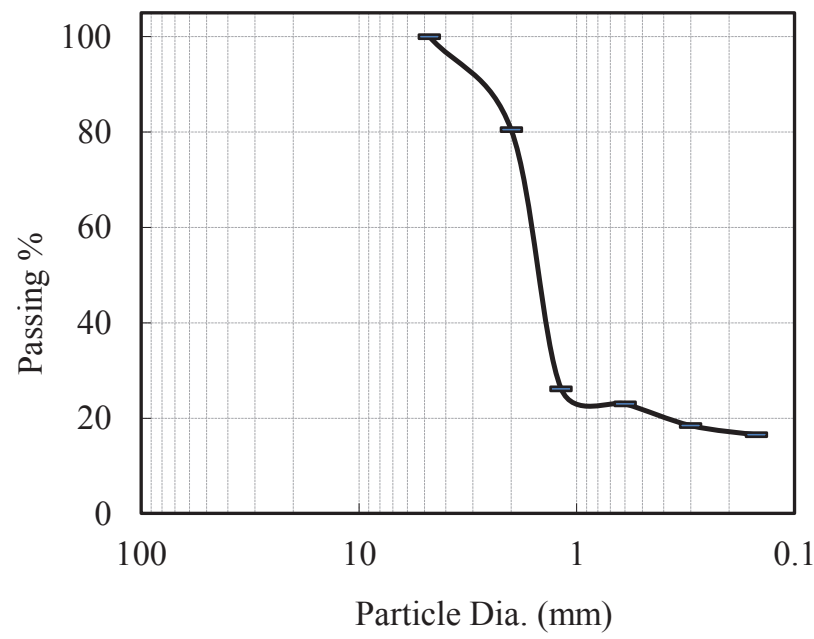

Fig. 3. Grain size distribution of AC used

7- Carbon tetrachloride activity

The adsorption of saturated carbon tetrachloride vapour is the measurement of the porosity of an activated carbon.

The adsorption is the process in which atoms, ions or molecules from a substance (it could be gas, liquid or dissolved solid) adhere to a surface of the adsorbent. Adsorption is a process which is based on surface and that is different from absorption which is the process in which a fluid is dissolved by a liquid. In adsorption a film of adsorbate is created on the surface while absorption involves the entire volume of the absorbing substance.

\subsubsection{Laboratory tests}

The testing program of the samples of the clayey soil were tested to calculate their physical and chemical properties in the natural state. And the testing program of the samples of the clayey soil, were stabilized with different percentages $(0,3,5,7$, and $9 \%)$ of activated carbon materials (AC), included Atterberg's limits, compressibility, Specific Gravity, Unconfined compressive strength natural and improved soil when activated carbon content increase with curing $(0,1,7$, 14,28 ) days, consolidation and CBR test [4].

\section{Atterbeg limits:}

- Liquid limit test: The test of liquid limit was carried out on samples passing sieve (No. 40) $0.425 \mathrm{~mm}$, by using Casagrande's apparatus liquid limit apparatus as per the procedures laid down in ASTM D 4318 with clayey soils with $(0,3,5,7 \& 9 \%)$ of activated carbon additive.

- Plastic limit test: The test of plastic limit was carried out on samples passing $0.425 \mathrm{~mm}$ (No. 40) sieve, by using per the procedures laid down in ASTM D 4318 with clayey soils with $(0,3,5,7$ \& 9\%) of activated carbon additive.

Specific gravity: The specific gravity (Gs) test was carried out on the soil according to ASTM 854.

Compaction: This test was carried out according to the specifications ASTM D 1557. The specimen's diameter was of $102 \mathrm{~mm}$ and $116 \mathrm{~mm}$ height. The degree of compaction of soil was effected by the engineering soil characteristics such as compressibility, stiffness, swell potential, permeability and shrink. So that, it is important to achieve the desired degree of relative compaction and it's necessary to meet the required soil characteristics.

Static compaction: To prepare samples for unconfined compressive strength UCS and consolidation tests, air dry soil was mixed with the required amount of distilled water to give initial moisture content. The soil was mixed thoroughly by hand and stored in a desiccators for 18 hours to obtain uniform moisture distribution.

The static compaction method was followed the preparation of soil samples using a special mold and a compression testing machine. Load was applied statically to the soil sample at a compression rate of $0.04 \mathrm{~mm} / \mathrm{sec}$. until the depth of penetration approach the required height. The load was maintained on the specimen for about five minutes after reaching the required height to prevent the occurrence of rebound after static load removal.

UCS: the unconfined compressive test was carried out according to the specifications ASTM D 2166. The sample of UCS test had $38 \mathrm{~mm}$ in diameter and $76 \mathrm{~mm}$ in 
length. The dry unit weight of $17.6 \mathrm{kN} / \mathrm{m}^{3}$ value of the natural soil at the moisture content $17 \%$, and improved soil when activated carbon content increase with curing $(0,1,7,14,28)$ days.

CBR: This test was carried out according to the specifications (ASTM D 1883). The sample of CBR had $152 \mathrm{~mm}$ in diameter and $126 \mathrm{~mm}$ in length. The testes were performed at the optimum moisture content (OMC) and maximum dry unit weight (MDD) values of the natural soil.

Swelling: Consolidation test was carried out according to the specifications (ASTM D 2435). The setup was used for determining the cyclic. The sample which used had $75 \mathrm{~mm}$ in diameter and $19 \mathrm{~mm}$ in height. The samples were prepared at Proctor's dry densities.

\section{Presentation and discussion of test results}

\subsection{Effect on Atterberg's limit}

\subsubsection{Liquid limit (L.L.)}

Figure (4) is shown the variation of liquid limit for soil stabilized with different percentages of activated carbon. There were decreases in liquid limit at all soil-activated carbon combinations. The cause of the ash is that the activated carbon coats and binds all clay particles which possesses little cementitious value and large particles.

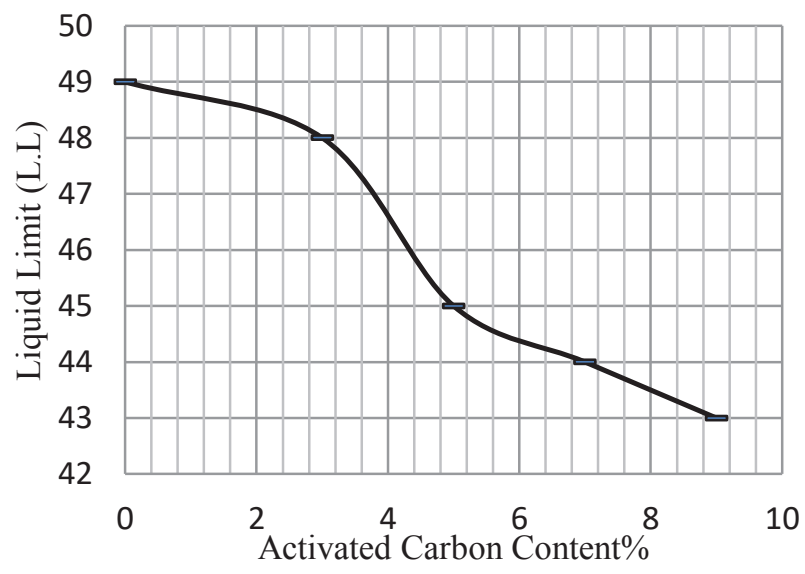

Fig. 4. Liquid Limit of Activated carbon mixed soil

\subsubsection{Plastic limit (P.L.)}

Plastic limits shown in Figure (5), it was noticed that with increasing $\mathrm{AC}$ content there was increase in plastic limit. It is very clear the increase in the plastic limit when the activated carbon content is increased in the combinations. The exchange in cationic reaction adduced for the liquid limit is also applicable here.

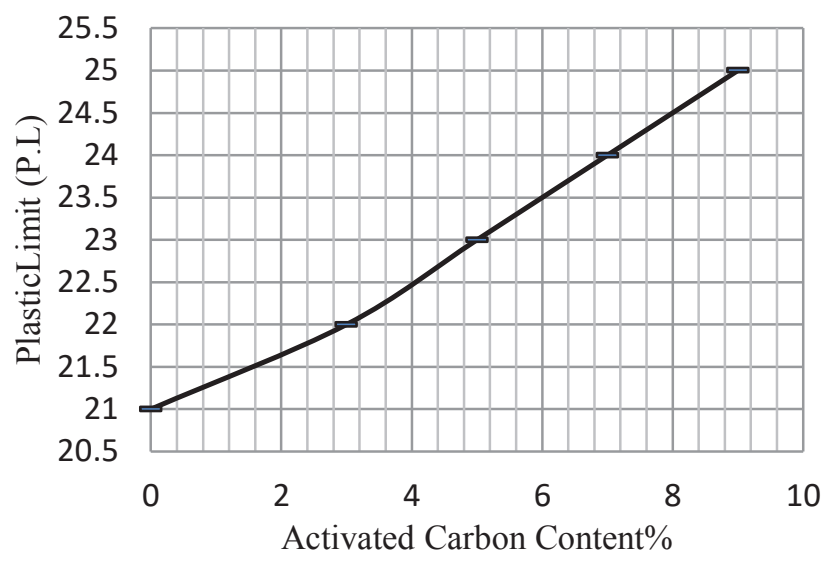

Fig. 5. Plastic Limit of Activated carbon mixed soil

\subsubsection{Effect on plasticity index (P.I.)}

The Figure (6) clarified the changes of P.I for the different percentages of soil - activated carbon combination. It was observed that increasing activated carbon content at all percentages for both stabilized samples of soil-activated carbon leads to decreases in plasticity index. The results obtained by other investigators (Sridharan et al. 1986, Athanasopoulou 1995) [5-6] agree with this. They observed a significant reduction in the liquid limit and plasticity index when treating a fine-grained soil with additives.

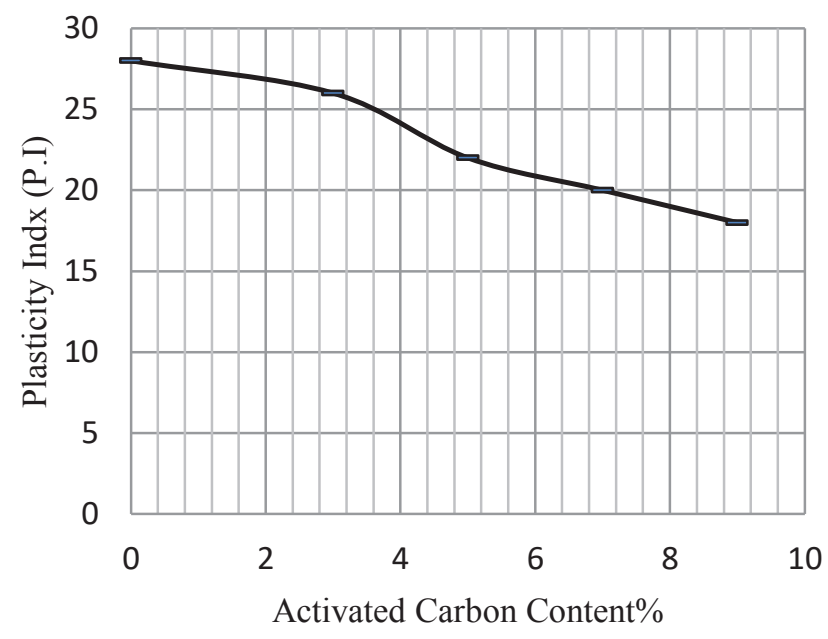

Fig. 6. Plasticity Index of Activated Carbon mixed soil

\subsection{Effect on specific gravity}

Figure (7) is shown the variations of specific gravity of the soil with different percentages from activated carbon combinations. It is observed that the increase of $\mathrm{AC}$ to the soil made a decreasing in results of the specific gravity value. This decrease in specific gravity can be attributed to the lower specific gravity value of $\mathrm{AC}$ (i.e. 2.05). 


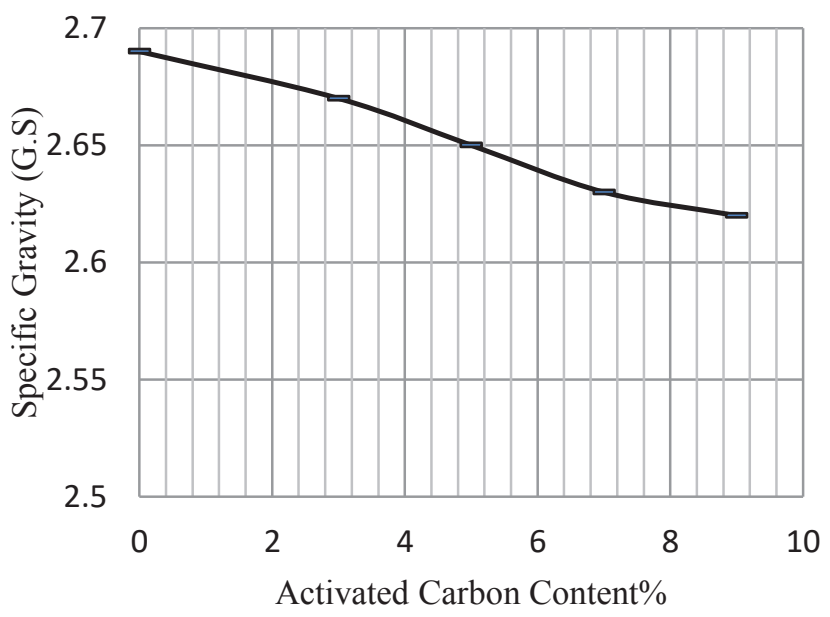

Fig. 7. Specific gravity of Activated Carbon mixed soil

\subsection{Effect on compaction}

Figure (8) is shown the variation of compaction characteristics for the soil with different percentages of $\mathrm{AC}$ between optimum moisture content (OMC) and maximum dry density (MDD. Figure (9) illustrates the relation between MDD and $\mathrm{AC}$ content and the results shows that the MDD decreases with the increase in the $\mathrm{AC}$ content. Figure (10) illustrates the relation between $\mathrm{OMC}$ and $\mathrm{AC}$ content and the results shows that when increase in $\mathrm{AC}$ content, the $\mathrm{OMC}$ is increased too.

The decrease in the MDD can be attributed to the replacement of soil and by the $\mathrm{AC}$ in the mixture which has relatively lower specific gravity (2.04) compared to that of the soil which is 2.69 (Ola 1975; Osinubi and Katte 1997). It may also be attributed to coating of the soil by the AC which result to large particles with larger voids and hence less density (Osula 1991). The decrease in the MDD may also be explained by considering the $\mathrm{AC}$ as filler (with lower specific gravity) in the soil voids.

The reason behind increasing in optimum moisture content (OMC) with increase in $\mathrm{AC}$ contents is that increase in AC content causes adsorption of a high amount of water which expel the clay particles and the water takes its place.

When the soil is mixed with additives that lead to improvement in variations of the engineering characteristics and improve the physical and chemical properties of the soil such as carbonation, flocculation of clay and cation exchange (Jawad et al., 2014; Zumrawi and Hamza, 2014) [7-8].

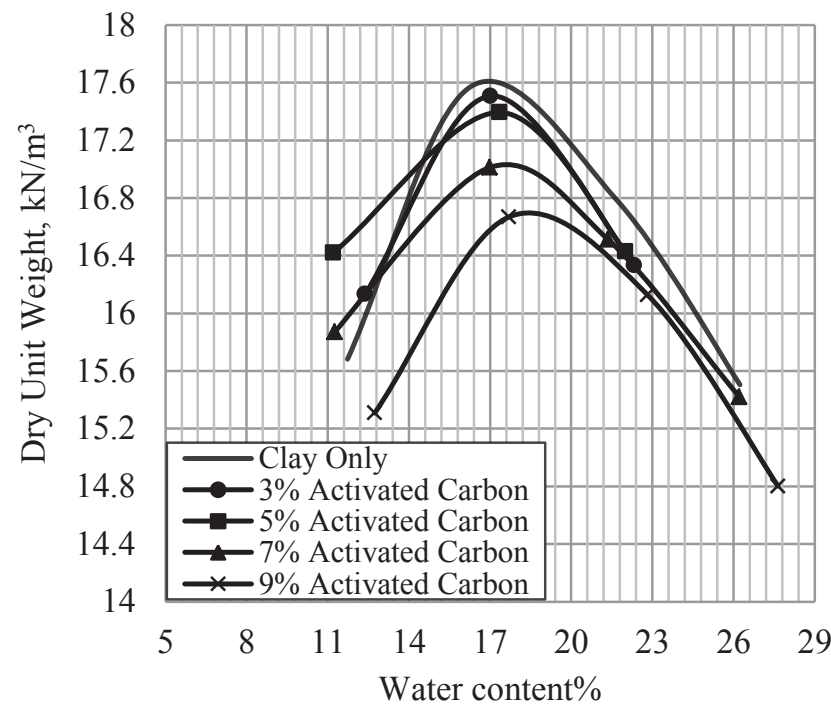

Fig. 8. Variation of MDD and OMC with AC content for clay soil.

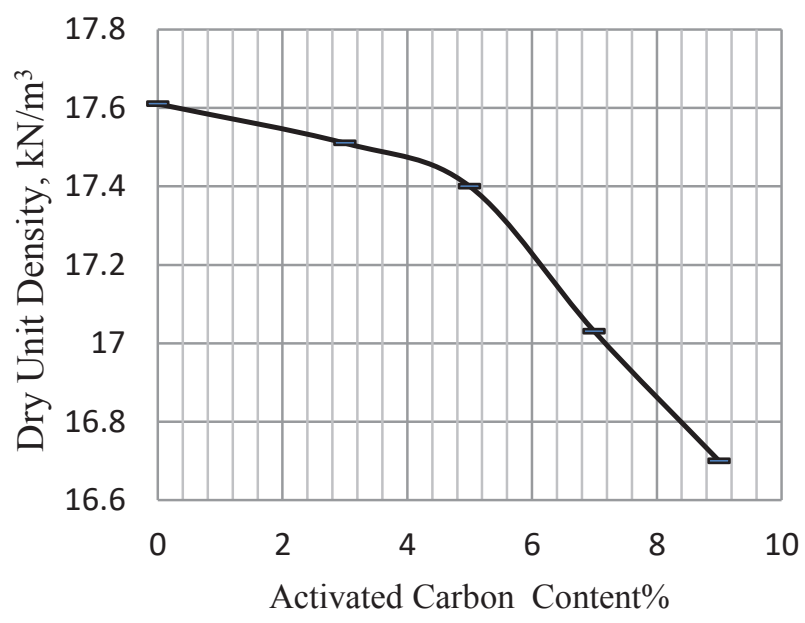

Fig. 9. MDD of AC Mixed Soil

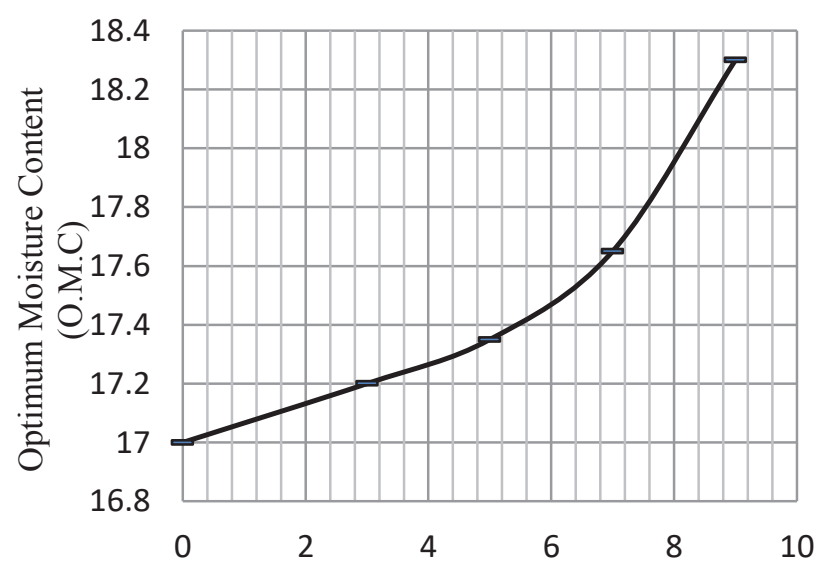

Activated Carbon Content $\%$

Fig. 10. OMC of AC Mixed Soil 


\subsection{Effect on unconfined compressive strength}

Compressive strength (UCS) of a soil is an important factor to assess the stress of the soil and to assess the materials which can use in pavement and constructions. It is one of the important tests which used to determinate of amount of additives required to improve the soil (Singh and Singh 1991). UCS tests were performed on natural soil with $(0 \%, 3 \%, 5 \%, 7 \%$ and $9 \%$ $\mathrm{AC})$ as shown in Figures $(11,12,13,14$ and 15) respectively. There is no clear variation in UCS for the clay only without AC. With increase of the curing time periods from 0 to 28 days and changes in UCS with the increase in $\mathrm{AC}$ from 3\% to $9 \%$ while increasing curing period from 0 to 28 day are shown in Figure (16) which illustrates two important points. The first is the increase in stiffness of the soil with increasing the percentage of $\mathrm{AC}$ as an additive, this is clearly shown in the gradual change of the shapes of curves with increasing $\mathrm{AC}$ content for four curing periods. The second point is the increase in stiffness of the model test cured for 28 days as compared to the corresponding model test cured for 7 days; this increase is due to hardening process that developed during 28 days curing period. The compaction method - (i.e. modified test instead of the used standard Proctor's test) would have a significant impact on the strength values (Ghosh 2013) [9].

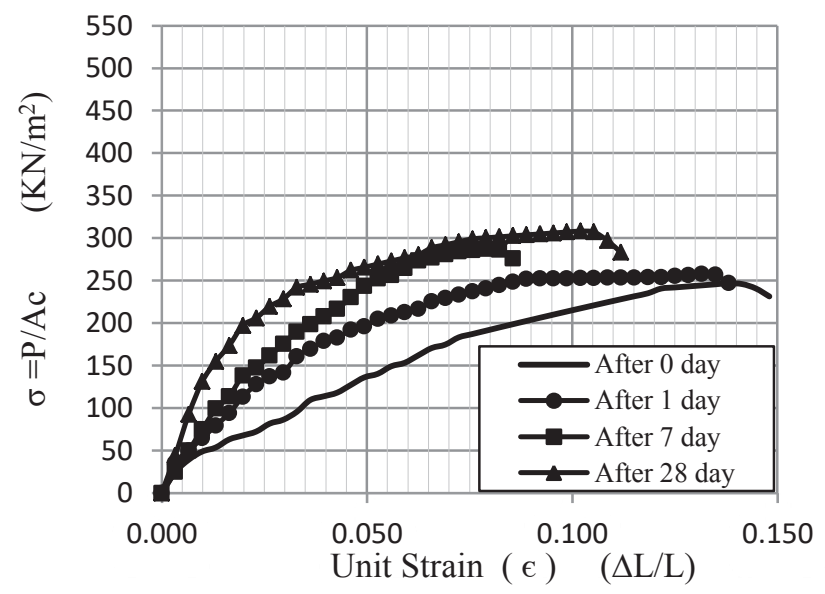

Fig. 11. Stress-strain relationship from unconfined compression test for samples treated by $0 \% \mathrm{AC}$.

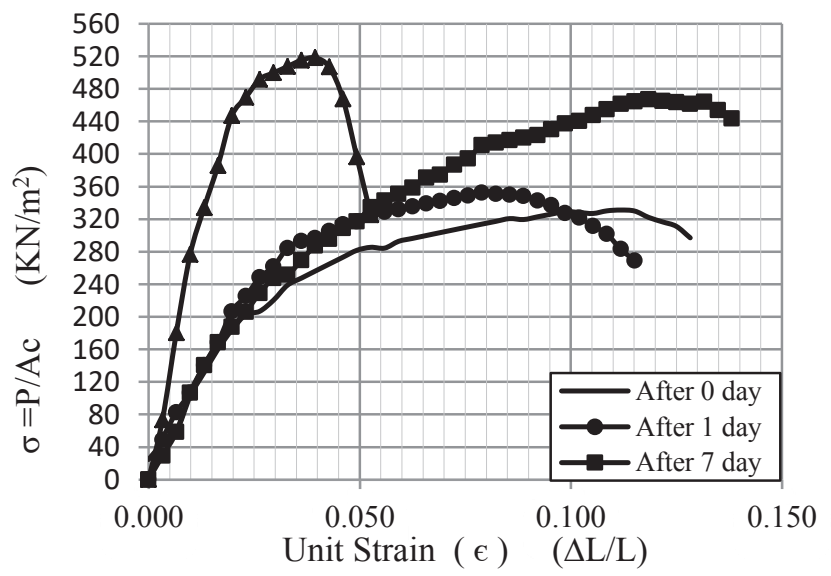

Fig. 12. Stress-strain relationship from unconfined compression test for samples treated by $3 \% \mathrm{AC}$.

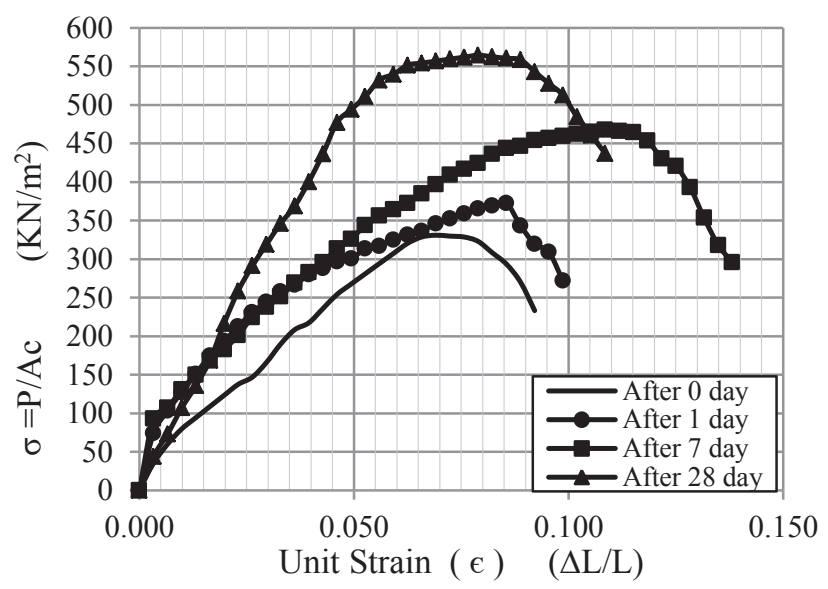

Fig. 13. Stress-strain relationship from unconfined compression test for samples treated by $5 \% \mathrm{AC}$.

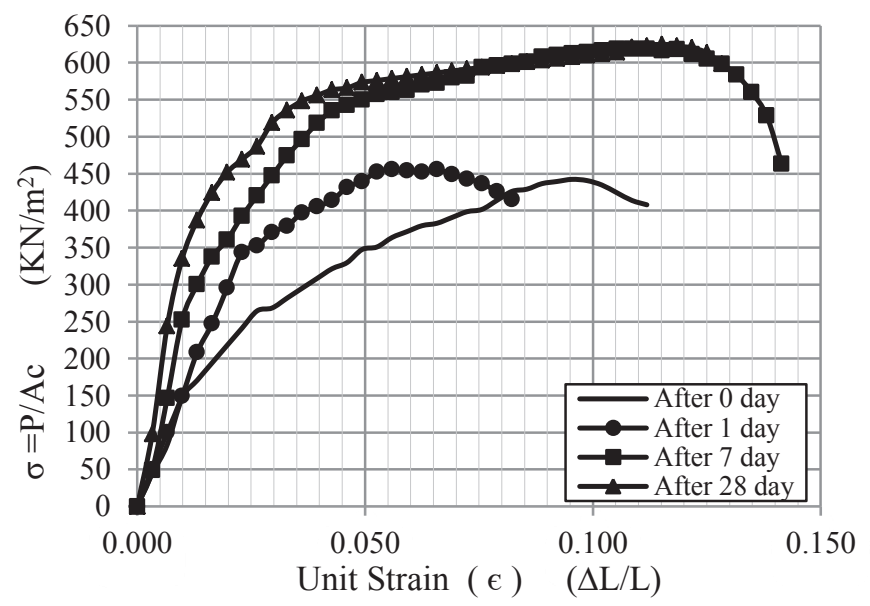

Fig. 14. Stress-strain relationship from unconfined compression test for samples treated by $7 \% \mathrm{AC}$.

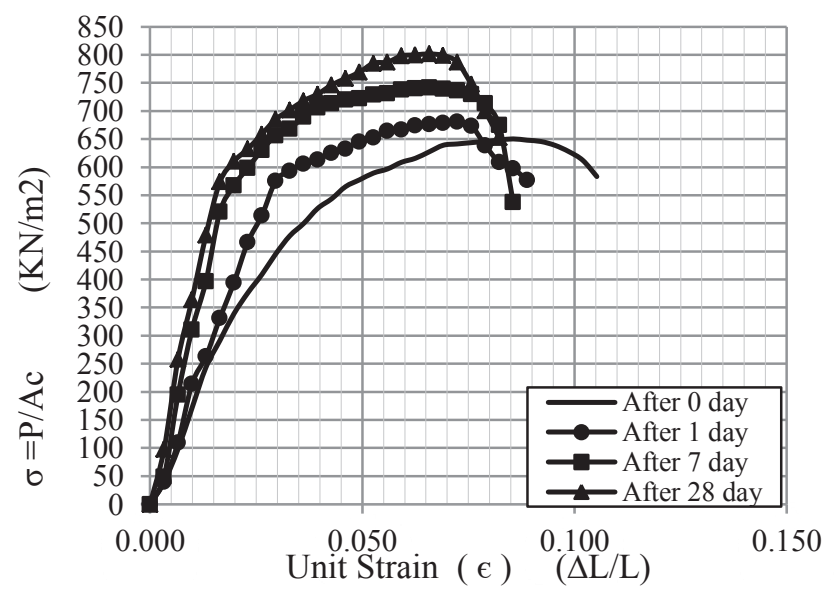

Fig. 15. Stress-strain relationship from unconfined compression test for samples treated by $9 \% \mathrm{AC}$. 


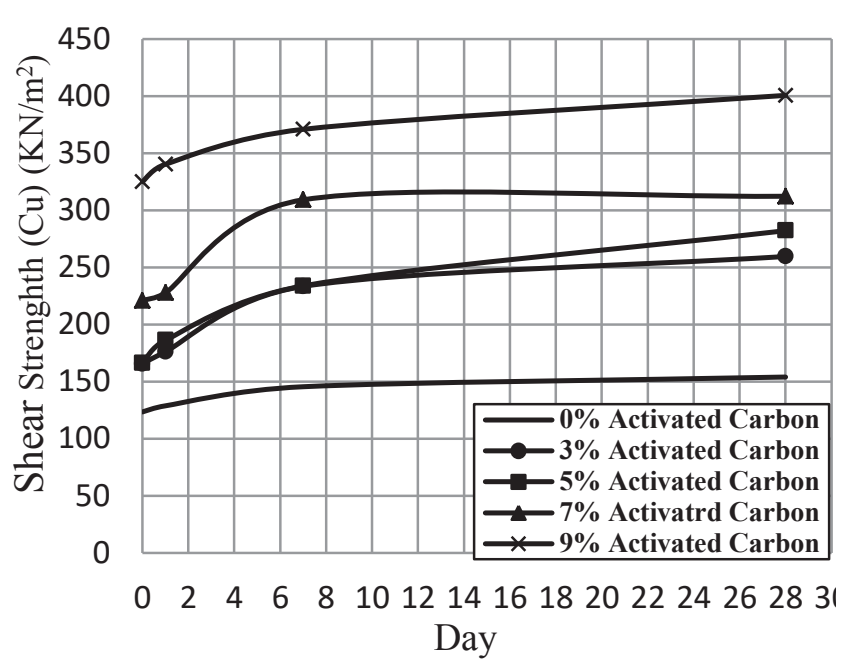

Fig. 16. Variation of UCS with AC

\subsection{Effect on California bearing ratio (CBR)}

The California bearing ratio (CBR), is an indicator of bearing capacity of the soil and the strength of the soil. This type of test is used to facilitate the design of the lower layers of the pavement such as base layer and subbase layer.

The test is performed by measuring the pressure required to penetrate a soil sample with a plunger of standard area. The pressure of soil which is determined from the test is divided by pressure of crushed rock for the same penetration. The CBR test is described in ASTM Standards D1883-05 (for laboratory-prepared samples) and D4429 (for soils in place in field) which this research depends on is AASHTO T193. This test, which is simple, fast and reliable have been used to verify the stabilization of weak soils by adding physical and chemical additives (Raymond et al 2007 and Joel Beeghly et al 2010) [1011]. Figure (17) is shown the test results of CBR with each percentage of activated. Figure (18) is shown the increase in CBR value of the soil with increase of percentages of $\mathrm{AC}$ content. It can be seen that addition of $\mathrm{AC}$ increased the $\mathrm{CBR}$ of the soil.

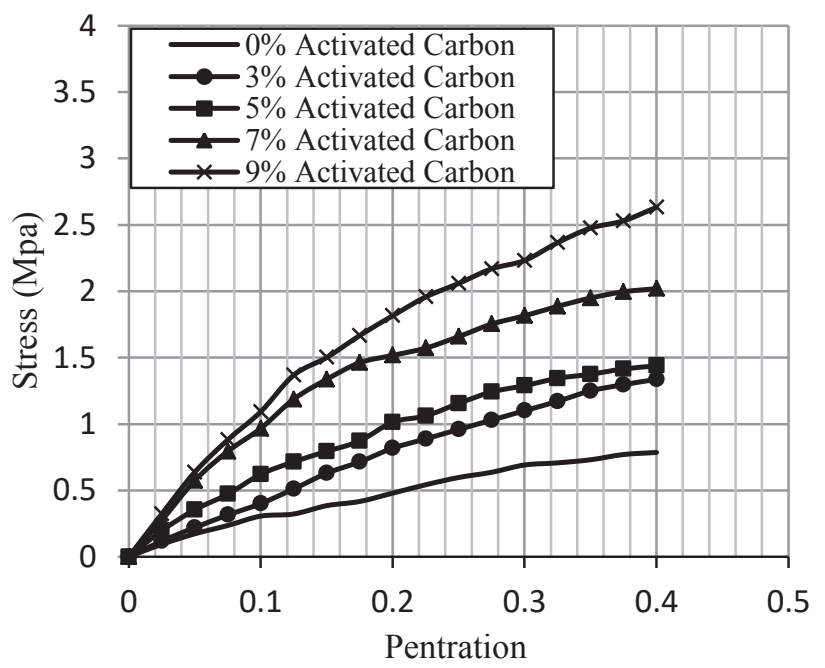

Fig. 17. CBR of AC Mixed Soil

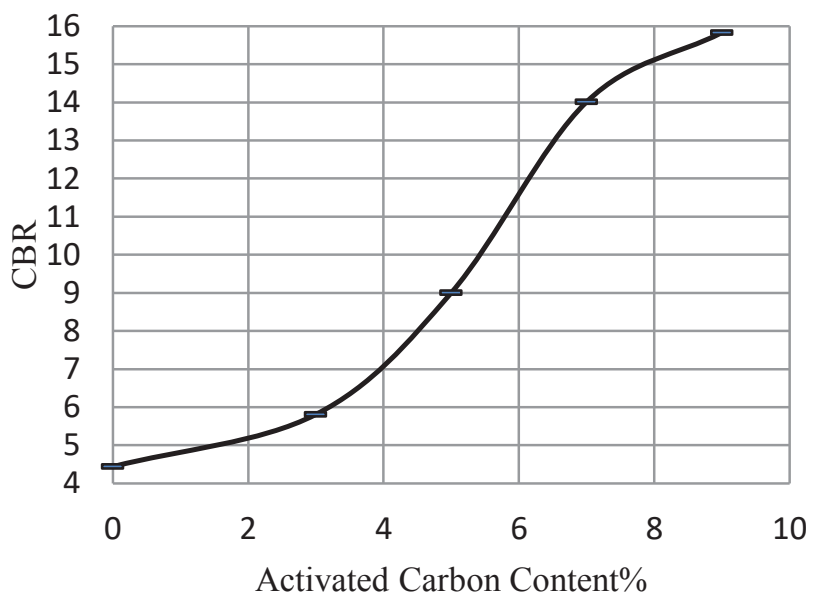

Fig. 18. CBR with AC Percentages

\subsection{Effect on compressibility characteristics}

A consolidation ring of $7.5 \mathrm{~cm}$ diameter and $1.9 \mathrm{~cm}$ height was used in testing. All samples of soil were compacted by static compaction at $\gamma_{\text {dry }}$ of $17.6 \mathrm{kN} / \mathrm{m}^{3}$ and water content of $17 \%$. Every sample was soaked in water after the test. Figure (19) is shown the variation of in void ratio with effective stress of consolidation in semi log scale for the soil with each percentage of AC content.

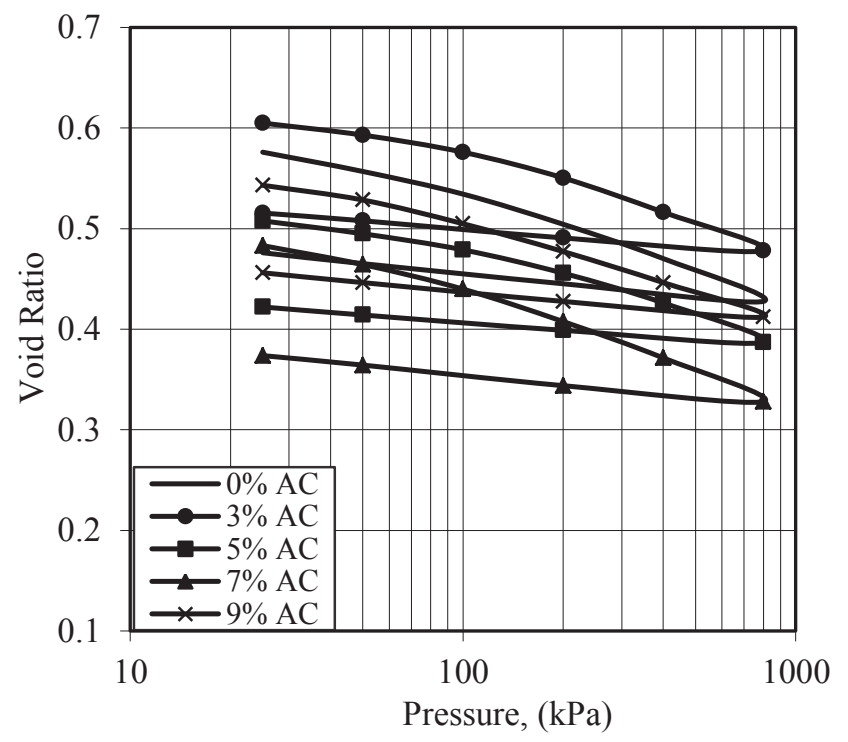

Fig. 19. e-Log Relationship for different percent of AC

\subsection{Effect on swell and swell pressure for prepared soil}

The soil samples used in this test were prepared in the laboratory by mixing natural soil with $30 \%$ percentage of bentonite and improved by adding $0,3,5,7$ and $9 \%$ AC powder (passing from $0.6 \mathrm{~mm}$ ). Static compaction method was followed for preparing the soil samples using a special mold and a compression testing 
machine. Load was applied statically to the soil sample at a compression rate of $0.04 \mathrm{~mm} / \mathrm{sec}$. until the depth of penetration approach the required Height of $1.5 \mathrm{~cm}$, the samples were prepared at a dry unit weight of 17.61 $\mathrm{kN} / \mathrm{m}^{3}$ and moisture content of $17 \%$. The load was maintained on the specimen for about five minutes after reaching the required height to prevent the occurrence of rebound after static load was removed. Figures (20), (21) and (22) show the effect of the soil stabilized with different percentage of AC content on the free swell and swell pressure. From these figures we can see that there is rapid decrease in free swell and swell pressure with the increasing percentages of $\mathrm{AC}$ content. The reduction in the swelling and swelling pressure values of the improved soils may be due to the addition of non expansive silt size particles to the expansive soil and the interaction between the soil and activated carbon particles. Consequently, the specific surface area and water affinity of the inspected soil samples decrease, which refers to the reduction in the swell-shrinkage values such as free swell and swelling pressure.

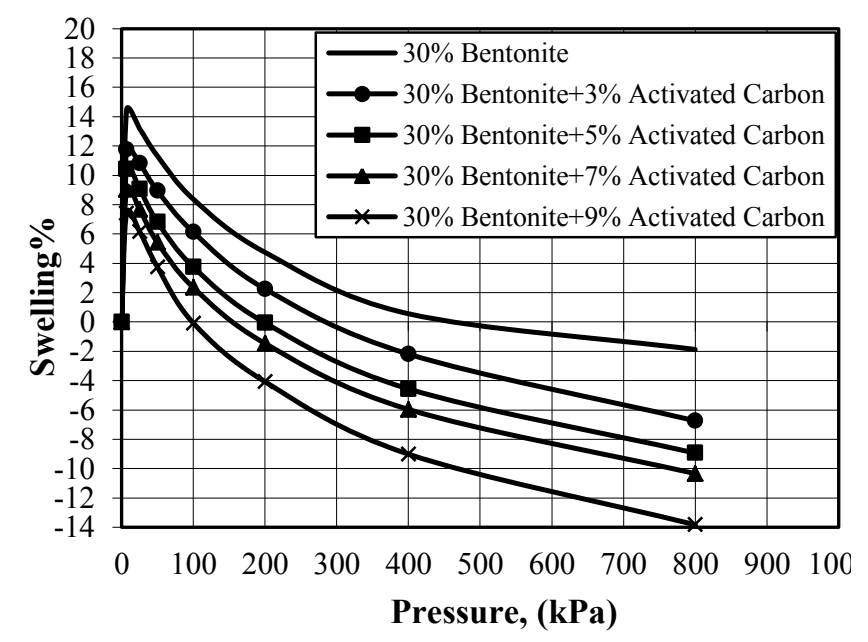

Fig. 20. Relationship between swelling and pressure for prepared soil with $3,5,7$ and $9 \%$ Ac.

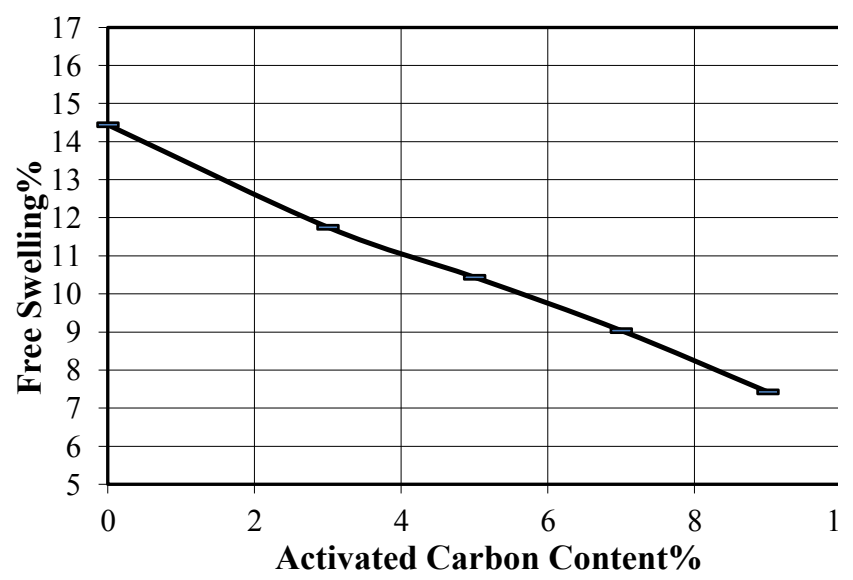

Fig. 21. Relationship between free swelling and AC content.

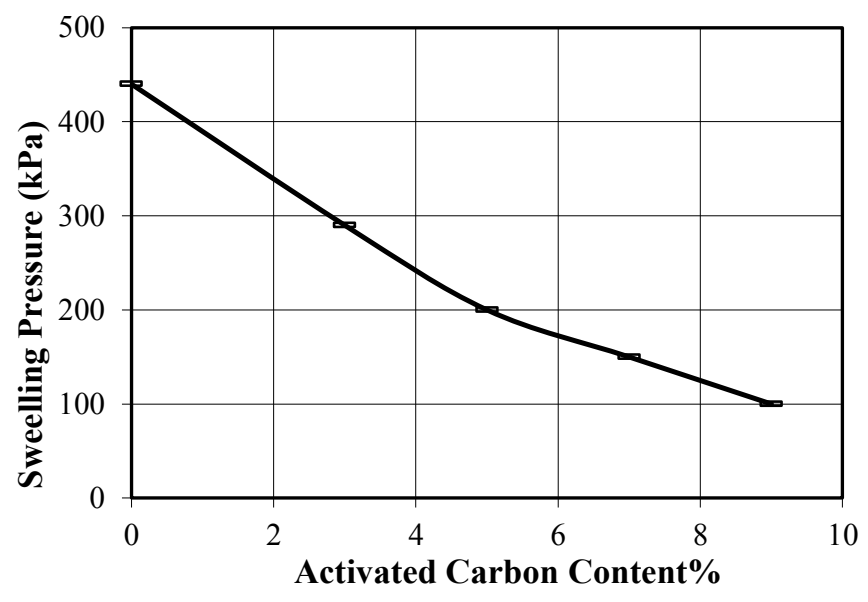

Fig. 22. Relationship between swelling pressure and AC content.

\section{Conclusions}

Based on the results obtained it can be concluded that:

1. The specific gravity decreases with increase of AC percentage.

2. The liquid limit slightly decreases with increase of AC percentage.

3. The plastic limit slightly increases with increase of AC percentage.

4. The plasticity index decreases with increase of AC percentage.

5. There is a clear decrease in maximum dry unit weight with the increase of percentage of the AC content.

6. Optimum moisture content increases with increase of AC percentage.

7. The unconfined compression strength was increased by increase both of activated carbon percent and the period of curing.

8. Free swell and swell pressure highly increases with increase of bentonite percentage. While free swell and swell pressure rapidly decrease with the increase of the percentage of the AC content.

\section{References}

1. K. Terzaghi R.B. Peck, Soil Mechanics in Engineering Particle, $2^{\text {nd }}$ edition, john Wiley and Sons, New York (1976).

2. P. Buringh, Netherlands by H. Veenman and Zonen N.V , Wageningen (1960).

3. B.M. Das, Principles of Foundation Engineering, 5th Edition Thomoson learning Academic Resource, United State of Amarican (2004).

4. J.E. Bowels, Foundation Analysis and Design, 5th ed. Mc Graw-Hill book company, New York (1996).

5. A. Athanasopoulou, Application to Soils Encountered in the Area of Thrace, Ph.D. Dissertation, Department of Civil Engineering, Democritus University of Thrace (1995).

6. A. Sridharan, S.M. Rao, N.S. Murthy, ASTM 
Geotechnical Testing Journal (1986).

7. I.T. Jawad, M.R. Taha, Z.H. Majeed, T.A. Khan, Research Journal of Applied Sciences, Engineering and Technology (2014).

8. M.M.E. Zumrawi, O.S.M. Hamza, International Journal of Science and Research (IJSR) (2014).

9. R. Ghosh, Journal of Civil Engineering and Construction Technology (2013).

10. N. Raymond, Yong, Ouhadi. R. Vahid, Applied Clay Science (2007).

11. H. Joel, Beeghly, Michael. Schrock, International Journal of Soil, Sediment and Water (2010). 